\title{
Percentile values of the standing broad jump in children and adolescents aged 6-18 years old
}

Ewan Thomas (1), Luca Petrigna (1), Garden Tabacchi (1), Eduardo Teixeira (2), Simona Pajaujiene (3), David J. Sturm (4), Fatma Nese Sahin (5), Manuel GómezLópez (6), Jelena Pausic (7), Antonio Paoli (8), Marianna Alesi (9), Antonino Bianco (1)

(1) Sport and Exercise Research Unit, Department of Psychology, Educational Science and Human Movement, University of Palermo, Palermo, Italy; (2) CIEQV, Escola Superior de Desporto de Rio Maior, IPSantarém, Portugal; (3) Department of Coaching Science, Lithuanian Sports University, Kaunas, Lithuania; (4) Associate Professorship of Educational Science in Sport and Health, Technical University of Munich, Uptown Munich Campus D, Georg-BrauchleRing 60/62, 80992 Munich, Germany; (5) Faculty of Sport Sciences. Coaching Education Department, Ankara University, Ankara, Turkey; (6) Department of Physical Activity and Sport. International Campus of Excellence "Mare Nostrum", Faculty of Sports Sciences, University of Murcia, San Javier, Spain; (7). Faculty of Kinesiology, University of Split, Croatia; (8) Department of Biomedical Sciences, University of Padova, Padua, Italy; (9) Department of Psychology, Educational Science and Human Movement, University of Palermo, Palermo, Italy

This article is distributed under the terms of the Creative Commons Attribution Noncommercial License (CC BY-NC 4.0) which permits any noncommercial use, distribution, and reproduction in any medium, provided the original author $(s)$ and source are credited.

\begin{abstract}
The standing broad jump (SBJ) is a valid, reliable and feasible field-based test, which can evaluate explosive strength of the lower limbs and physical fitness. This study aimed to provide normative data for the SBJ for male and female children and adolescents and describe differences in performance between age groups and genders. A total number of 2140 children and adolescents, sampled in seven European nations have been included for analysis. The SBJ was performed to derive percentile values for gender and each age group. In general, males have greater jumping performance compared to females. Data demonstrate a linear increase in the jumping distance for both males and females until adolescence. However, such increase is evident in males up to 16-17 years old, whereas in females a plateau value is met at 12-13 years old, with a subsequent decrease in the jumping performance. No differences were present in jumping performance between male and female children, however differences between male and female adolescents were evinced. The study has provided percentile values useful to monitor the physical fitness status of children and adolescents.
\end{abstract}

Key Words: standing broad jump, normative data, children, adolescents

Eur J Transl Myol 30 (2): 240-246, 2020

Muscular fitness is an important health-related aspect, ${ }^{1}$ a fundamental component for complex athletic tasks but also during the execution of simple everyday life tasks. ${ }^{2}$ The importance of taking care and monitor such system since a young age is highlighted by the fact that it is positively associated with bone health while it is inversely associated with central adiposity, cardiovascular diseases and metabolic risk factors, ${ }^{3}$ and clustered metabolic risk. ${ }^{4}$ Furthermore, muscular fitness may reduce the risk of insulin sensitivity, important aspects either in a healthy population or for those who are exposed to metabolic risk factors. ${ }^{5,6}$
Muscular fitness corresponds to the level of muscular strength of both the upper and the lower limbs and an evaluation strongly associated with tests for the upper (basketball throw and push-ups) and lower limbs (countermovement jump and squat jump) is the standing broad jump (SBJ). ${ }^{7}$ This test is designed to measures lower limb muscular fitness and explosive muscular strength of children, adolescents and adults. ${ }^{7,8}$ Moreover, this test provides the opportunity to monitor gains after training, to identify sports talent and for pre-recruitment testing in institutions where other measurement instruments are not applicable. ${ }^{9}$ Finally, the SBJ is 
considered the most valid and reliable field-based muscular fitness test in children and adolescents, ${ }^{7,10,11}$ and is also applied to measure anaerobic power of the lower limbs. ${ }^{9}$

One of the best ways to monitor the muscular fitness status of children and adolescents is through specific gender and age normative data. Several studies have been performed from different geographical locations such as Australia, ${ }^{12,13}$ Colombia, ${ }^{14}$ Colombia-India, ${ }^{15}$ China, ${ }^{16}$ Hungary, ${ }^{17}$ Greece, ${ }^{18}$ Spain, ${ }^{19}$ or as part of larger transnational studies, ${ }^{20,21}$ however such results are limited to confined age ranges or national populations. A recent study has proposed percentile values for the main tests of the Alpha-fit test battery (handgrip strength, standing long jump, and $4 \times 10 \mathrm{~m}$ shuttle run test), ${ }^{22}$ one of the most adopted batteries in Europe to assess physical fitness in children and adolescents. ${ }^{23}$ Kolimechkov, et $\mathrm{al}^{22}$ to reach their goal, collected data from different studies, ${ }^{20,} 24$ filling the gap between ages through linear interpolation. However, the authors stated that this was a temporary solution until such gap was filled by experimental research. ${ }^{22}$ Considering the aforementioned reasons, this study aims to provide normative data regarding male and female children and adolescents aged 6 to 18 years old from seven different European countries.

\section{Materials and Methods}

\section{Participants}

The sample recruited was composed of school-children aged between 6 and 18 years old. These were recruited as part of different projects, namely the ASSO project, ${ }^{25}$ the ESA program, ${ }^{26,27}$ and Alfabetizzazione Motoria. ${ }^{28}$ The data were recruited from primary and secondary schools and sports centres located in Italy, Lithuania, Germany, Spain, Portugal and Croatia, with the addition of data from Turkey. The locations were those of the partners of the above mentioned projects. A consent form has been signed by the parent or the legal guardian of each participant and such condition was required to participate in the study. Only children who were able to perform the required motor task were included for investigation. Children were excluded if presented medical issues that could influence the jumping performance; or physical and mental disabilities. A total number of 2140 participants, 1176 males and 964 females were finally included. Further details regarding age and anthropometric parameters are shown in Table 1.

The local Ethical Committee of the University approved the project and the study is in accordance with the Helsinki Declaration of 1975, as revised in 2013.

\section{Standing broad jump}

The standing broad jump test was performed on a hard surface. The participants stood in a standing position with the heels on the starting line and the feet parallel. The participants, after being instructed by the investigator had to jump as far as possible in a horizontal direction. No indication had been given on the movement of the legs or the arms, so, the participants could perform a selfdecided depth countermovement of the legs and perform a free-arm amplitude swing. The participants had to land with both feet together and block the jump without further advancement. All tests were performed three times with a five-minute rest between each attempt. The distance was measured with a tape, in centimetres, from the starting line to the heel of the closest foot to the starting line and the best score of the three attempts was

Table 1. Descriptive characteristics of the sample

\begin{tabular}{|c|c|c|c|c|c|c|c|c|c|}
\hline & \multicolumn{3}{|c|}{ Total } & \multicolumn{3}{|c|}{ Male } & \multicolumn{3}{|c|}{ Female } \\
\hline Age & $\mathrm{n}$ & Height $(\mathrm{cm})$ & Mass (kg) & $\mathrm{n}$ & Height $(\mathrm{cm})$ & Mass (kg) & $\mathrm{n}$ & Height $(\mathrm{cm})$ & Mass $(\mathrm{kg})$ \\
\hline 6 & 105 & $124.2 \pm 9.7$ & $28.9 \pm 7.3$ & 51 & $126.8 \pm 11.1$ & $31.4 \pm 8.6$ & 54 & $122.1 \pm 8.6$ & $26.7 \pm 4.9$ \\
\hline 7 & 109 & $130.5 \pm 13.3$ & $31.9 \pm 9.9$ & 54 & $132.0 \pm 14.3$ & $34.3 \pm 11.3$ & 55 & $129.4 \pm 12.7$ & $29.9 \pm 8.1$ \\
\hline 8 & 189 & $133.9 \pm 6.1$ & $32.1 \pm 7.9$ & 105 & $133.7 \pm 5.7$ & $34.5 \pm 9.3$ & 84 & $134.8 \pm 6.4$ & $30.1 \pm 4.7$ \\
\hline 9 & 167 & $142.8 \pm 11.6$ & $39.9 \pm 11.2$ & 87 & $140.1 \pm 8.6$ & $36.5 \pm 8.9$ & 80 & $138.9 \pm 6.4$ & $41.4 \pm 13.1$ \\
\hline 10 & 223 & $139.9 \pm 7.9$ & $35.5 \pm 9.3$ & 122 & $139.7 \pm 8.1$ & $35.1 \pm 8.6$ & 101 & $140.4 \pm 7.7$ & $36.2 \pm 10.3$ \\
\hline 11 & 145 & $142.6 \pm 7.0$ & $36.2 \pm 6.1$ & 72 & $144.1 \pm 6.4$ & $37.5 \pm 61.2$ & 73 & $141.9 \pm 7.3$ & $31.9 \pm 20.7$ \\
\hline 12 & 140 & $145.1 \pm 7.7$ & $40.8 \pm 7.7$ & 82 & $148.3 \pm 8.4$ & $48.8 \pm 10.2$ & 58 & $141.9 \pm 6.9$ & $32.8 \pm 5.1$ \\
\hline 13 & 109 & $162.4 \pm 6.1$ & $54.9 \pm 8.3$ & 56 & $164.7 \pm 5.4$ & $56.6 \pm 8.7$ & 53 & $156.8 \pm 3.3$ & $51 \pm 6.2$ \\
\hline 14 & 200 & $163.5 \pm 7.7$ & $57.0 \pm 10.2$ & 112 & $166.2 \pm 8.1$ & $59.7 \pm 11.4$ & 88 & $159.5 \pm 4.8$ & $52.9 \pm 6.5$ \\
\hline 15 & 174 & $167.0 \pm 8.3$ & $64.1 \pm 15.4$ & 93 & $170.8 \pm 7.8$ & $68.6 \pm 16.8$ & 81 & $161.0 \pm 5.0$ & $56.9 \pm 9.2$ \\
\hline 16 & 256 & $168.4 \pm 8.1$ & $61.7 \pm 12.2$ & 149 & $172.1 \pm 7.4$ & $65.7 \pm 12.9$ & 107 & $162.2 \pm 5.7$ & $55.1 \pm 7.2$ \\
\hline 17 & 199 & $168.8 \pm 7.9$ & $66.1 \pm 13.3$ & 128 & $173.0 \pm 5.7$ & $70.5 \pm 12.4$ & 71 & $161.5 \pm 5.7$ & $57.9 \pm 10.7$ \\
\hline 18 & 124 & $168.5 \pm 11.2$ & $66.9 \pm 14.7$ & 65 & $176.1 \pm 7.7$ & $73.6 \pm 14.1$ & 59 & $160 \pm 7.5$ & $59.6 \pm 7.5$ \\
\hline Total & 2140 & $156.9 \pm 18.2$ & $53.8 \pm 18.4$ & 1176 & $161.6 \pm 18.4$ & $58.1 \pm 19.4$ & 964 & $150.9 \pm 15.9$ & $47.9 \pm 14.9$ \\
\hline
\end{tabular}

Data are presented as means \pm standard deviation. 
Table 2. Percentile values for male children and adolescents for the standing broad jump

\begin{tabular}{|c|c|c|c|c|c|c|c|c|c|}
\hline Age/Percentile & 10 & 20 & 30 & 40 & 50 & 60 & 70 & 80 & 90 \\
\hline 6 & 101 & 113 & 116 & 119 & 124 & 125 & 128 & 131 & 138 \\
\hline 7 & 103.6 & 116 & 119.9 & 122.2 & 125 & 127 & 132.2 & 135.8 & 153.2 \\
\hline 8 & 100 & 109.6 & 119.8 & 130 & 133 & 137.4 & 145 & 150 & 159.2 \\
\hline 9 & 104.6 & 116.2 & 120 & 127 & 133 & 138.6 & 147.2 & 159.8 & 179.4 \\
\hline 10 & 111.1 & 124.2 & 129.3 & 135 & 142 & 148 & 152.7 & 160 & 172.9 \\
\hline 11 & 117.4 & 137.2 & 143 & 148 & 152.5 & 155.6 & 164 & 168 & 177.7 \\
\hline 12 & 137.4 & 150 & 158 & 161 & 163.5 & 169.6 & 178 & 182.6 & 192.8 \\
\hline 13 & 135 & 149 & 153.5 & 160 & 167.5 & 175 & 179.5 & 183 & 188 \\
\hline 14 & 130.3 & 141 & 153.3 & 160.4 & 166 & 178 & 183 & 192.4 & 205 \\
\hline 15 & 132.2 & 145 & 153 & 164.8 & 170 & 176.4 & 181.8 & 192 & 197.8 \\
\hline 16 & 135 & 149.2 & 164.4 & 172.2 & 180 & 190 & 200 & 210.4 & 223.2 \\
\hline 17 & 150 & 165 & 175 & 184.8 & 195 & 200 & 210 & 216.2 & 228 \\
\hline 18 & 146.2 & 154.8 & 160 & 172.6 & 178 & 190.2 & 196 & 200.2 & 219.8 \\
\hline
\end{tabular}

All data are expressed in $\mathrm{cm}$.

retained for investigation. The Standard Operating Procedures (SOP) can be found elsewhere. ${ }^{11}$

\section{Statistical Analysis}

Analysis were performed using SPSS (version 25 for Windows; IBM, Chicago, IL, USA). Means and Standard deviations were calculated for each age group from 6 to 18 years old and stratified by gender. Subsequently, values from the 10th to the 90th percentiles were derived, calculated for each 10th percentile. Data have been tested for normality using the Kolmogorov-Smirnov test. Being that all data presented a normal distribution, comparisons between age groups within each gender and between genders have been performed through parametric evaluation. ANOVA was performed to evaluate differences between age groups within each gender. Welch T-tests for independent samples have been performed between the same age groups across genders. $\alpha$ value was set at 0.05 . The percentile values were finally represented through a smoothed percentile chart, which was obtained through a sixth order polynomial representation for each age group and percentile value using GraphPad PRISM (Version 8.0.1).

\section{Results}

Tables 2 and 3 report the percentile values of each age group of the sample for males and females, respectively. For each percentile category there is a linear increase of the jumping distance up to the age of 16-17 years. No statistical difference has been evinced between contiguous age groups, despite the significant difference $(p<0.001)$ highlighted by the ANOVA on the whole sample. The same trend is shown for the male participants, who show a linear increase in the jumping performance up to 16-17 years old for all percentile values (Table 2 and Figure 1). No statistical difference has been shown between contiguous age groups, despite the significant difference $(\mathrm{p}<0.001)$ highlighted by the ANOVA on the whole sample. Female participants increase the jumping performance up to the age of 12-13 years with a subsequent decrease from 14 years old onwards (Table 3 and figure 2). No statistical difference has been found between contiguous age groups, despite the significant difference $(\mathrm{p}<0.001)$ highlighted by the ANOVA on the whole sample.

Table 3. Percentile values for female children and adolescents for the standing broad jump

\begin{tabular}{ccccccccccccc}
\hline Age/Percentile & $\mathbf{1 0}$ & $\mathbf{2 0}$ & $\mathbf{3 0}$ & $\mathbf{4 0}$ & $\mathbf{5 0}$ & $\mathbf{6 0}$ & $\mathbf{7 0}$ & $\mathbf{8 0}$ & $\mathbf{9 0}$ \\
\hline $\mathbf{6}$ & 95.1 & 104.6 & 108.9 & 113 & 115.5 & 117.8 & 122 & 127.4 & 133.4 \\
\hline $\mathbf{7}$ & 94.4 & 105.6 & 112.6 & 120 & 122 & 123.4 & 128 & 134 \\
\hline $\mathbf{8}$ & 88 & 101.2 & 108 & 114.6 & 122 & 129.8 & 135.4 & 147.4 & 161.8 \\
\hline $\mathbf{9}$ & 100 & 112.6 & 117.7 & 120 & 122.5 & 129.4 & 135 & 143.6 & 154.5 \\
\hline $\mathbf{1 0}$ & 109 & 116 & 123 & 130 & 138 & 149 & 154 & 162 & 175 \\
\hline $\mathbf{1 1}$ & 106.2 & 122.4 & 139.6 & 143.8 & 152 & 155 & 160 & 165 & 174.8 \\
\hline $\mathbf{1 3}$ & 122.2 & 131.4 & 139.1 & 146.8 & 150.5 & 155 & 160 & 163.2 & 174.9 \\
\hline $\mathbf{1 4}$ & 121.4 & 129 & 130.6 & 135 & 142 & 149.2 & 154.4 & 160 \\
\hline $\mathbf{1 5}$ & 111.4 & 116.4 & 125.2 & 130 & 137.5 & 145 & 150.9 & 160.6 & 167.3 \\
\hline $\mathbf{1 6}$ & 112 & 121 & 127 & 134 & 139 & 145 & 150 & 160 \\
\hline $\mathbf{1 7}$ & 101.6 & 115 & 120 & 127.2 & 131 & 140 & 148.4 & 156 & 164.8 \\
\hline $\mathbf{1 8}$ & 105 & 108 & 112 & 120 & 126 & 134 & 140 & 152 \\
\hline
\end{tabular}

All data are expressed in $\mathrm{cm}$. 


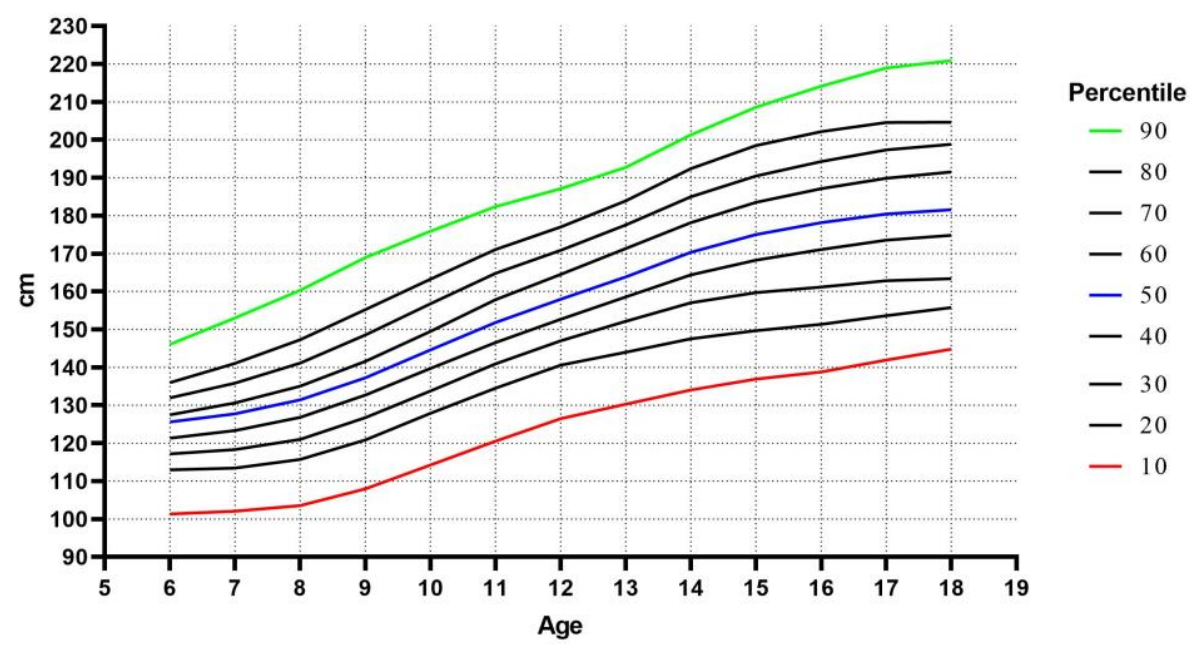

Fig 1. The male participants show an almost linear increase in the jumping performance up to 16-17 years old for all percentile values

When comparing age groups across genders, no significant difference in jumping performance is present between males and females from 6 to 12 years old. From 13 to 18 years of age, significant differences are shown for similar age groups between genders with greater performance measures in the male population $(\mathrm{p}<0.01)$.

The percentile measures highlight differences regarding the jumping performance between male and female participants.

\section{Discussion}

The study has provided normative data for European children and adolescents aged between 6 and 18 years for the SBJ. The results of the present study are partially comparable with the values of the study of Kolimechkov and Alexandrova. ${ }^{22} \mathrm{~A}$ distinction between male and female participants seems evident. As for the Colombian, ${ }^{14}$ Colombian-Indian, ${ }^{15}$ Chinese, ${ }^{16}$ and Spanish, ${ }^{19}$ normative data, girls showed an increase in SBJ performance up to the age of 12, with a subsequent decline from 13 years onwards. Male participants do not show such decline in performance, presenting conversely a linear increase of the horizontal jump performance, data comparable with the study by Kolimechkov and Alexandrova, ${ }^{22}$ and other studies. ${ }^{14-16,19}$

It is known that from 6 years of age until 12 to 13 there is a gradual linear increase in muscular explosive strength, ${ }^{29}$ therefore such increase in SBJ performance for both male and female was expected. During this early stage of life, sports practice is less competitive and

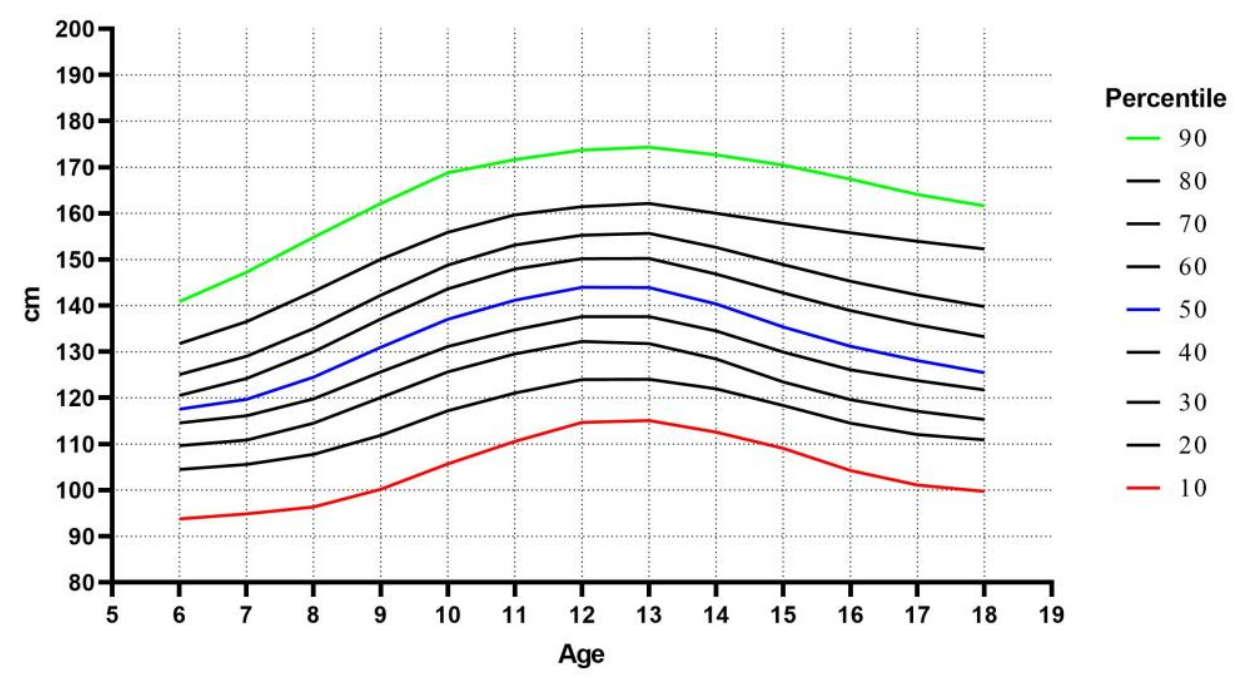

Fig 2. Female participants increase the jumping performance up to the age of 12-13 years with a subsequent decrease from 14 years old onwards 
consequently it is more enjoyable than in secondary school. ${ }^{30}$ During adolescence, other factors influence the SBJ performance and consequently the physical fitness related to physical and psychological characteristics. From a physical point of view, boys present an association between biological maturity and strength. ${ }^{29}$ During puberty, boys present a faster increase of steroid hormones, growth hormone and bone mineral content. ${ }^{16}$. Considering that adolescents are influenced by their peers in terms of physical activity and diet, ${ }^{31}$ it is likely that boys tend to practice a sport with the purpose of performance and competition while girls mainly practice physical activity for aesthetic purposes. In addition, different studies have tried to understand the reasons that push adolescents to be physically active. ${ }^{32-35}$ Males tend to be positively influenced by friends and peers and have higher self-motivation and enjoyment in practicing physical activities during adolescence. Females, instead, suffer more from the transition from primary to secondary school, which leads to a change of their environment and this could be a cause of the reduction of the physical activity practiced, ${ }^{36}$ a factor that is probably influenced by the social environment in which they live. ${ }^{30,37}$ Furthermore, internal and external factors can influence girls' decision to practice physical activities as the sensation of not correctly performing the required sport skills, ${ }^{37}$ the faulty perceptions of their abilities and self-consciousness ${ }^{38}$ the limited sporting activities that women can practice due to the limited number of programs and services available in schools which are specific for girls. ${ }^{39}$ In the work of Slater and Tiggemann, ${ }^{30}$ girls expressed different reasons for not attending sporting activities, as losing interest, feeling not competent for the required activity or not having enough time. Other factors reported by the authors concerning girls' withdrawal from sporting activities were the feeling that some activities were typically masculine or had the fear to become too muscular. All these factors alone or combined may result in a higher activity engagement in boys compared to girls, which may explain the decline in physical performance from 13 years old onwards in female participants. This is an interesting point since muscle weakness, ${ }^{2}$ but not the decay rate of aging, ${ }^{41}$ of the female compared to the male lasts for the lifetime.

The major strength of this study is that the data arise from seven European countries, which enables the analysis of transnational data, including children and adolescents over a large age group from different countries. Furthermore, these data could be used to detect children and adolescents that could be in a "warming zone" (e.g. under 10th percentile) when related to health prevention or select athlete in a "interesting zone" (e.g. over 90th percentile) in a school or public contest. Clearly, the data doesn't reflect the European population due to its relatively small sample according to age and country. To preserve a larger and more representative sample a stratification of data was not performed, although more specific and detailed information could have described cultural differences of the sample. Furthermore, other methodological issue is related to the study design, indeed, normative data should be created from a longitudinal study when it is evaluated a parameter related to growing, and this is a cross-sectional study. One last limitation is that, even if the same standard operating procedure has been adopted and an online training has been performed before the study, the data were collected by different teachers, sport science specialists, physical educators.

In conclusion, the study provides SBJ normative data for children and adolescents. It has been noted that SBJ presents a linear increase in the jumping performance in both male and female until adolescence. In adolescents, males continued a linear increase of the SBJ performance up to the age of 17 years old while female presented a plateau after 13 years old, after which a decrease was present. This study establish a reference point for further investigations in this research area.

\section{List of acronyms}

SBJ - standing broad jump

SOP - Standard Operating Procedures

\section{Authors contributions}

ET, LP, and AB developed the study concept and design as the data analysis and interpretation. ET, GT, ETex, SP, DS, NS, MGL, JP, MA, AB collected the data for the present manuscript. ET, LP, GT, AP, MA and AB wrote the first draft while ETex, SP, DS, NS, MGL, JP critically reviewed and added their contribution to the second version of the manuscript. All authors approved the final version of the manuscript and agree to be accountable for all aspects of the work.

\section{Acknowledgments}

\section{Funding}

The study is part of the Enriched Sport Activities (ESA) Program, which is an Evidence-based Practice Exercise Project cofounded by the Erasmus + Programme of the European Union (Key action: Sport-579661-EPP-12016-2-IT-SPO-SCP)

\section{Conflict of Interest}

The authors declare they have no conflict of interest.

\section{Ethical Publication Statement}

We confirm that we have read the Journal's position on issues involved in ethical publication and affirm that this report is consistent with those guidelines.

\section{Corresponding Author}

Luca Petrigna, PhD student, Sport and Exercise Sciences Research Unit, University of Palermo, Via Giovanni Pascoli 6 - 90144, Palermo, Italy.

ORCID iD: 0000-0002-8106-537X

E-mail: luca.petrigna@unipa.it 
E-mail and ORCID iD of co-authors

Ewan Thomas: ewan.thomas@unipa.it ORCID iD: 0000-0001-5991-8316

Garden Tabacchi: tabacchi.garden@libero.it ORCID iD: 0000-0002-7619-5153

Eduardo Teixeira:

eduardoteixeira@esdrm.ipsantarem.pt

ORCID iD: 0000-0002-4326-4175

Simona Pajaujiene: Simona.Pajaujiene@lsu.lt ORCID iD: 0000-0001-5306-4188

David J. Sturm: david.sturm@tum.de ORCID iD: 0000-0003-0372-041X

Fatma Nese Sahin: nesesahin@ankara.edu.tr ORCID iD: 0000-0002-8777-5807

Manuel Gómez-López: mgomezlop@um.es ORCID iD: 0000-0002-4595-3994

Jelena Pausic: jelenap@kifst.hr ORCID iD: 0000-0001-7360-7282

Antonio Paoli: antonio.paoli@unipd.it ORCID iD: 0000-0003-0474-4229

Marianna Alesi: marianna.alesi@unipa.it ORCID iD: 0000-0002-7372-3205

Antonino Bianco: antonino.bianco@unipa.it ORCID iD: 0000-0001-8334-6581

\section{References}

1. Caspersen CJ, Powell KE, Christenson GM. Physical activity, exercise, and physical fitness: definitions and distinctions for health-related research. Public Health Rep 1985;100:126-31.

2. Suchomel TJ, Nimphius S, Stone MH. The importance of muscular strength in athletic performance. Sports Med 2016;46:1419-49. doi: 10.1007/s40279-016-0486-0. Review.

3. Smith JJ, Eather N, Morgan PJ, et al. The health benefits of muscular fitness for children and adolescents: a systematic review and meta-analysis. Sports Med 2014;44:1209-23. doi: 10.1007/s40279-014-0196-4.

4. Artero EG, Ruiz JR, Ortega FB, et al. Muscular and cardiorespiratory fitness are independently associated with metabolic risk in adolescents: the HELENA study. Pediatr Diabetes 2011;12:704-12. doi: 10.1111/j.1399-5448.2011.00769.x.

5. Shaibi GQ, Cruz ML, Ball GD, et al. Effects of resistance training on insulin sensitivity in overweight Latino adolescent males. Med Sci Sports Exerc 2006;38:1208-15. doi: 10.1249/01.mss.0000227304.88406.0f.

6. Benson AC, Torode ME, Singh MAF. Muscular strength and cardiorespiratory fitness is associated with higher insulin sensitivity in children and adolescents. Int J Pediatr Obes 2006;1:222-31. doi: $10.1080 / 17477160600962864$.
7. Castro-Pinero J, Ortega FB, Artero EG, et al. Assessing muscular strength in youth: usefulness of standing long jump as a general index of muscular fitness. J Strength Cond Res 2010 Jul;24:1810-7. doi: 10.1519/JSC.0b013e3181ddb03d..

8. Ortega FB, Cadenas-Sanchez C, Sanchez-Delgado $\mathrm{G}$, et al. Systematic review and proposal of a fieldbased physical fitness-test battery in preschool children: the PREFIT battery. Sports Med 2015;45:533-55. doi: 10.1007/s40279-014-0281-8.

9. Krishnan A, Sharma D, Bhatt M., Dixit A., Pradeep P. Comparison between standing broad jump test and Wingate test for assessing lower limb anaerobic power in elite sportsmen. Med J Armed Forces India 2017;73:140-5. doi: 10.1016/j.mjafi.2016. 11.003.

10. Artero EG, Espana-Romero V, Castro-Pinero J, et al. Criterion-related validity of field-based muscular fitness tests in youth. J Sports Med Phys Fitness 2012;52:263-72.

11. Bianco A, Jemni M, Thomas E, et al. A systematic review to determine reliability and usefulness of the field-based test batteries for the assessment of physical fitness in adolescents - The ASSO Project. Int J Occup Med Environ Health 2015;28:445-78. doi: 10.13075/ijomeh.1896.00393

12. Catley MJ, Tomkinson GR. Normative healthrelated fitness values for children: analysis of 85347 test results on 9-17-year-old Australians since 1985. Brit J Sport Med 2013;47:98-108. doi: 10.1136/bjsports-2011-090218.

13. Hardy LL, Merom D, Thomas M, Peralta L. 30-year changes in Australian children's standing broad jump: 1985-2015. J Sci Med Sport 2018;21:105761. doi: 10.1016/j.jsams.2018.04.005

14. Ramirez-Velez R, Martinez M, Correa-Bautista JE, et al. Normative reference of standing long jump for Colombian schoolchildren aged 9-17.9 Years: The FUPRECOL Study. J Strength Cond Res 2017;31:2083-90. doi: 10.1519/JSC.000000000000 1633.

15. Ramos-Sepulveda JA, Ramirez-Velez R. CorreaBautista JE, et al. Physical fitness and anthropometric normative values among Colombian-Indian schoolchildren. Bmc Public Health. 2016;16:962. doi: 10.1186/s12889-0163652-2.

16. Chung LMYC, Chow LPY, Chung JWY. Normative reference of standing long jump indicates gender difference in lower muscular strength of pubertal growth. Health. 2013;5:6-11. doi: 10.4236/health.2013.56A3002

17. Saint-Maurice PF, Laurson KR, Kaj M, Csanyi T. Establishing normative reference values for standing broad jump among Hungarian youth. Res Q Exerc Sport 2015;86:S37-44. doi: 10.1080/ 02701367.2015.1042416. 
18. Tambalis KD, Panagiotakos DB, Arnaoutis G, Sidossis LS. Endurance, explosive power, and muscle strength in relation to body mass index and physical fitness in greek children aged 7-10 years. Pediatr Exerc Sci 2013;25:394-406. doi: 10.1123/ pes.25.3.394. Epub 2013 Jul 12.

19. Ortega FB, Ruiz JR, Castillo MJ, et al. Healthrelated physical fitness according to chronological and biological age in adolescents. The AVENA study. J Sport Med Phys Fit 2008;48:371-9.

20. Ortega FB, Artero EG, Ruiz JR, et al. Physical fitness levels among European adolescents: the HELENA study. Brit J Sport Med 2011;45:20-9. doi: 10.1136/bjsm.2009.062679.

21. Tomkinson GR, Carver KD, Atkinson F, et al. European normative values for physical fitness in children and adolescents aged 9-17 years: Results from 2779165 Eurofit performances representing 30 countries. Brit J Sport Med 2018;52:1445-56. doi: 10.1136/bjsports-2017-098253.

22. Kolimechkov SP, Petrov L, Alexandrova A. Alphafit test battery norms for children and adolescents from 5 to 18 years of age obtained by a linear interpolation of existing European physical fitness references. European Journal of Physical Education and Sport Science [Online] 2019;5:1-14. doi: $105281 /$ zenodo. 2546360

23. Kolimechkov S. Physical Fitness assessment in children and adolescents: a systematic review. European Journal of Physical Education and Sport Science [Online] 2017;3:65-78.

24. De Miguel-Etayo P, Gracia-Marco L, Ortega FB, et al. Physical fitness reference standards in European children: the IDEFICS study. Int J Obes (Lond) 2014;38:S57-66. doi: 10.1038/ijo.2014.136.

25. Bianco A, Mammina C, Jemni M, et al. A Fitness Index model for Italian adolescents living in Southern Italy: the ASSO project. J Sports Med Phys Fitness 2016;56:1279-88. Epub 2015 Oct 16.

26. Tabacchi G, Lopez Sanchez GF, Sahin FN, et al. Field-based tests for the assessment of physical fitness in children and adolescents practicing sport: a systematic review within the ESA Program. Sustainability-Basel 2019, 11, 7187. doi:10.3390/ su11247187

27. Thomas E, Palma A. Physical fitness evaluation of school children in Southern Italy: a cross sectional evaluation. J Funct Morphol Kinesiol 2018;3:14. doi:10.3390/jfmk3010014

28. Thomas E, Bianco A, Tabacchi G, et al. Effects of a physical activity intervention on physical fitness of schoolchildren: the enriched sport activity program. Int $\mathbf{J}$ Environ Res Public Health. 2020;17:1723. doi: 10.3390/ijerph17051723

29. Buenen GT, Thomis M. Muscular strength development in children and adolescents. Pediatr
Exerc Sci 2000;12:174-97. doi: 10.1123/pes.12 .2 .174

30. Slater A, Thomis, M. Uncool to do sport: A focus group study of adolescent girls reasons for withdrawing from physical activity. Psychology of Sport and Exercise 2010;11:619-26. doi: 10.1016/j.psychsport.2010.07.006

31. Chung SJ, Ersig AL, McCarthy AM. The influence of peers on diet and exercise among adolescents: a systematic review. J Pediatr Nurs 2017;36:44-56. doi: 10.1016/j.pedn.2017.04.010.

32. Dias DF, Loch MR, Ronque ER. Perceived barriers to leisure-time physical activity and associated factors in adolescents. Cien Saude Colet 2015;20:3339-50. doi: 10.1590/1413-81232015 2011.00592014.

33. Fernandez-Prieto I, Gine-Garriga M, Canet Velez O. Barriers and motivations perceived by adolescents related to physical activity. Qualitative study through discussion groups. Rev Esp Salud Publica 2019;93:e201908047.

34. Galan-Lopez P, Ries F. Motives for exercising and associations with body composition in Icelandic adolescents. Sports (Basel) 2019;7:149. doi: 10.3390/sports 7060149

35. Tabacchi G, Faigenbaum A, Jemni M, et al. Profiles of physical fitness risk behaviours in school adolescents from the ASSO project: a latent class analysis. Int $\mathbf{J}$ Environ Res Public Health 2018;15:1933. doi: 10.3390/ijerph15091933

36. Knowles AM, Niven A, Fawkner S. A qualitative examination of factors related to the decrease in physical activity behavior in adolescent girls during the transition from primary to secondary school. J Phys Act Health 2011;8:1084-91. doi: 10.1123/ jpah.8.8.1084

37. Yungblut HE, Schinke RJ, McGannon KR. Views of adolescent female youth on physical activity during early adolescence. J Sports Sci Med 2012;11:39-50. eCollection 2012.

38. Coleman L, Cox L, Roker D. Girls and young women's participation in physical activity: psychological and social influences. Health Educ Res 2008;23:633-47. doi: 10.1093/her/cym040.

39. Craike MJ, Symons C, Zimmermann JAM. Why do young women drop out of sport and physical activity? A social ecological approach. Annals of Leisure Research. 2009;12:148-72. doi: 10.1080/ 11745398.2009.9686816

40. Gava P, Ravara B. Master World Records show minor gender differences of performance decline with aging. Eur J Transl Myol. 2019;29(3):8327. doi: 10.4081/ejtm.2019.8327.

Submission: April 21, 2020

Revision received: May 18, 2020 Accepted for publication: May 18, 2020 